\title{
COMPETÊNCIAS EMPREENDEDORAS DE PROPRIETÁRIOS FRANQUEADOS DE ESCOLAS DE IDIOMAS DO INTERIOR DO PARANÁ
}

DOI: 1014211/regepe33005

\author{
Vanessa Pagnoncelli - Universidade Estadual do Centro-Oeste Unicentro ${ }^{1}$ \\ Marcia Aparecida Zampier - Universidade Estadual do Centro-Oeste Unicentro ${ }^{2}$ \\ Silvio Roberto Stefano - Universidade Estadual do Centro-Oeste Unicentro ${ }^{3}$
}

Resumo: O objetivo geral do presente estudo é analisar as competências empreendedoras de proprietários franqueados de escolas de idiomas no interior do Paraná, de acordo com o modelo de Man e Lau (2000), e as expectativas futuras de crescimento. Para atingir esse objetivo foi realizado um estudo de multicasos e os dados foram coletados por meio de entrevistas com quatro participantes, sendo duas proprietárias de franquias de escolas de idiomas do interior do Paraná. Considera-se que este trabalho atingiu o objetivo proposto, uma vez que as competências puderam ser identificadas e analisadas dentro do modelo adotado e verificada a frequência com que cada uma foi identificada nos empreendedores participantes. Também foi possível verificar que os participantes buscam desenvolver suas competências e que possuem formas semelhantes de fazê-lo. Por fim, pode-se compreender que os franqueados possuem expectativa de crescimento devido à ocorrência de futuras competições esportivas no Brasil e ao aumento da classe $\mathrm{C}$.

Palavras-chave: Competências empreendedoras, franquias, expectativas de crescimento.

\section{ENTREPRENEURIAL SKILLS OF OWNERS OF FRANCHISEES OF LANGUAGE SCHOOLS OF THE INTERIOR OF PARANÁ}

Abstract: This study was conducted with the main objective of analyzing the entrepreneurial skills of owners of franchise of language schools in Paraná, Brazil, according to the model of Man and Lau (2000), and the expectation of future growth. To achieve this objective, it was realized a study of multi cases and data were collected through the application of an interview with four participants, including two owners of franchises of language schools the State of Paraná. It is considered that this work reached the objective proposed, since it could identify the entrepreneurial skills and analyze them according to the adopted model and also verified the frequency that with each one could be identified in the entrepreneurs participants. It could also be verified that the participants intend to develop their skills and have similar ways of doing it. Finally it could be seen that there is expectation about the growth of franchises due to the next sporting competitions that will happen in Brazil and also the increasing of class $\mathrm{C}$ in Brazil.

Keywords: entrepreneurial skills, franchising, growth expectations.

\footnotetext{
${ }^{1}$ E.mail: pagnoncelli.vanessa@gmail.com - Endereço: Rua Padre Honorino João Muraro, 875, Santa Cruz, Guarapuava, PR. CEP: 85015-430.

2 E.mail: marciazampier@gmail.com

${ }^{3}$ E.mail: professor-silvio@hotmail.com
}

PAGNONCELLI, V.; ZAMPIER, M. A.; STEFANO, S. R. Competências empreendedoras de proprietários franqueados de escolas de idiomas do interior do Paraná. Revista de

Empreendedorismo e Gestão de Pequenas Empresas, v. 3, n. 3, p. 129-160, 2014. 


\section{Introdução}

Atualmente, exige-se que o ser humano, desde muito cedo, inicie o desenvolvimento de suas capacidades, habilidades e aptidões ( $\mathrm{CHA})$, definidas como competências por Zarifian (2001), para que possam competir no feroz mercado de trabalho. Uma das competências é a de empreender, ou seja, ser uma pessoa criativa, marcada pela capacidade de estabelecer e atingir objetivos e manter alto nível de consciência do ambiente em que vive, usando-a para detectar oportunidades de negócios (FILION, 1999). Porém, questiona-se se todos têm a possibilidade de ser empreendedor, ou melhor, quais são as competências necessárias para se definir um bom empreendedor?

Primeiramente, cabe lembrar que empreender em um país como o Brasil, não é tarefa fácil, principalmente devido à alta carga tributária, onde as turbulências na economia são constantes e existem poucos incentivos para a abertura de novos negócios. Assim, as franquias se constituem como uma boa alternativa de empreendimento (LUCCHESI; MERLO; PITTA, 2005).

Por este motivo e pelas franquias de idiomas estarem muito em voga, atualmente, devido à procura pelo aprendizado de um novo idioma, uma vez que o Brasil foi sede da Copa do Mundo de 2014 e será das Olímpiadas de 2016 (MOREIRA, 2010), este foi o empreendimento escolhido para esta pesquisa. Demonstra-se assim, portanto, a atualidade deste estudo.

Com a finalidade de buscar uma resposta para a pergunta desta pesquisa e discutir a respeito destes temas, resolveu-se ir a campo e estabeleceu-se como objetivo geral: analisar as competências empreendedoras de proprietários franqueados de escolas de idiomas do interior do Paraná, de acordo com o modelo de Man e Lau (2000), e com as expectativas futuras de crescimento.

Para cumprir este objetivo, foram determinados os seguintes objetivos específicos: a) Conhecer o perfil dos proprietários franqueados e das escolas de idiomas; b) Identificar as competências empreendedoras de acordo com o Modelo de Man e Lau (2000) nos proprietários franqueados de escolas de idiomas; c) Verificar a frequência com que cada competência é demonstrada pelos 
empreendedores participantes; d) Verificar se os empreendedores buscam desenvolver suas competências empreendedoras ou se utilizam apenas as competências natas; e e) Verificar as expectativas por parte dos franqueados, de crescimento das franquias pesquisadas, tendo em vista o aumento da classe $\mathrm{C}$ e a ocorrência das mais importantes competições esportivas do mundo no Brasil.

\section{Fundamentação teórica}

\section{Empreendedorismo}

O conceito de empreendedorismo possui diversas concepções, pode ter diferentes interpretações e ser associado a diferentes contextos, porém possui tamanha relevância. Timmons (1994, p. 24) o descreve como: "uma revolução silenciosa que representará para o século XXI mais do que a revolução industrial representou para o século XX".

Para Dornelas (2008), os fatores associados a um maior índice de atividades empreendedoras atualmente são: percepção da oportunidade, fatores sociais e culturais, educação (Ensino Médio e Superior), participação das mulheres, experiência e suporte financeiro para os start-ups.

Essas atividades empreendedoras são diferenciadas conforme o porte $\mathrm{e}$ neste estudo, o foco será dado à microempresas que, segundo o Art. 2 da Lei no 9.317/96, "é a pessoa jurídica que tenha auferido, no ano-calendário, receita bruta igual ou inferior a $\mathrm{R} \$ 240.000,00$ " (BRASIL, 1996).

Em Filion (1999) encontra-se que Centilon e Say foram os pioneiros no estudo do empreendedorismo, ainda em 1800, e inseriram neste contexto o termo risco, pelo fato do empreendedor investir suas próprias economias no negócio. Da mesma forma, Marco Polo definiu o empreendedor como um ser que assume riscos de forma ativa. O empreendedor é, portanto, o personagem principal desta tão relevante atividade, justificando-se a necessidade de discutir também o seu conceito.

\section{Empreendedor}

PAGNONCELLI, V.; ZAMPIER, M. A.; STEFANO, S. R. Competências empreendedoras de proprietários franqueados de escolas de idiomas do interior do Paraná. Revista de

Empreendedorismo e Gestão de Pequenas Empresas, v. 3, n. 3, p. 129-160, 2014. 
Um conceito atual para o termo empreendedor é de Dornelas (2008, p. 37), no qual ele é definido como aquele que "detecta uma oportunidade e cria um negócio para capitalizar sobre ela, assumindo riscos calculados". Percebe-se que o risco comentado anteriormente não deixou de existir, mas com o tempo buscou-se estudar as variáveis para que pudesse ser calculado, a fim de tornar possível uma tomada de decisão com maior embasamento.

Já Filion (1999, p.18-19) propõe uma definição bastante ampla e abrangente, buscando um pouco de cada teoria, compondo-a da seguinte forma:

O empreendedor é uma pessoa criativa, marcada pela capacidade de estabelecer e atingir objetivos e que mantém alto nível de consciência do ambiente em que vive, usando-a para detectar oportunidades de negócios. [...] um empreendedor que continua a aprender a respeito de possíveis oportunidades de negócios e a tomar decisões moderadamente arriscadas, que objetivam a inovação, continuará a desempenhar um papel de empreendedor.

Ou seja, o autor mostra que não basta inovar uma vez para ser empreendedor, é preciso se reinventar e continuar aprendendo a fim de manter-se tomando decisões que tragam vantagens competitivas e novidades para seu negócio.

Quanto ao papel da família, Rae (2004) comenta que pode encorajar ou desestimular o indivíduo para sua formação da identidade empreendedora, dependendo das atitudes, expectativas e cobranças. Desta forma, demonstra-se a importância da família na vida dos empreendedores, seja apoiando e incentivando ou ajudando financeiramente.

É preciso ressaltar que o foco deste estudo está no empreendimento de franquias e segue a linha de pensamento de Hashimoto que, ao relembrar das definições de empreendedor, parte do conceito adotado neste trabalho, de que empreender é começar um novo negócio. Neste sentido, o franqueado é empreendedor, pois "ele está começando o seu negócio do zero, com algumas vantagens, é certo, mas ele tira o negócio do chão, bem dentro do conceito de empreendedorismo" (HASHIMOTO, 2010, p. 1).

PAGNONCELLI, V.; ZAMPIER, M. A.; STEFANO, S. R. Competências empreendedoras de proprietários franqueados de escolas de idiomas do interior do Paraná. Revista de

Empreendedorismo e Gestão de Pequenas Empresas, v. 3, n. 3, p. 129-160, 2014. 
Desta forma, o empreendedor será tratado como franqueado, uma vez que, como citado anteriormente, o foco deste trabalho é o empreendimento de franquias.

\section{Franquias}

Segundo Mauro (1994, apud GUEDES; TRIGO, 2009), a criação de uma rede de igrejas controladas pelo Vaticano nos primórdios do cristianismo configurou o início do franchising ${ }^{i}$. Porém, como forma de negócio, considera-se que as franquias tiveram seu início nos Estados Unidos depois da guerra civil, quando a empresa Singer, que vendia máquinas de costura, estabeleceu uma rede de revendedores (MENDELSOHN, 1994 apud LUCCHESI; MERLO; PITTA, 2005).

Conforme Dahab (1996, apud LUCCHESI; MERLO; PITTA, 2005), as franquias só ganharam grande projeção após a Segunda Guerra Mundial, quando o governo norte americano disponibilizou linhas especiais de financiamento para os militares que retornavam ao país. Segundo o autor, atualmente, as franquias são uma forma específica de gestão empresarial amplamente utilizada em todo mundo e uma das mais eficientes estratégias para expansão das pequenas e médias empresas.

A International Franchise Association (IFA) define franquia como sendo a "relação contratual entre o franqueador e 0 franqueado, na qual o franqueador oferece ou se obriga a manter um contínuo interesse no negócio do franqueado, em campos como o know-how e a formação da empresa" (GUEDES; TRIGO, 2009, p. 44-45).

Cabe então, distinguir estes dois personagens importantes. Em primeiro lugar, aparece o franqueador, que é o proprietário do negócio original, aquele que detém direitos sobre a marca, sobre o produto ou o processo. Devido ao negócio estar bem sucedido, o empreendedor resolve ampliar seus negócios e, dentre as várias estratégias de crescimento, resolve franqueá-lo, permitindo que outras pessoas possam replicar suas unidades em outras localidades, sob regras e condições préestabelecidas e compartilhando os resultados (HASHIMOTO, 2010).

Outro personagem é o franqueado, ou seja, o sujeito que deseja abrir um negócio próprio e escolhe uma franquia a fim de reduzir os riscos da incerteza e 
inexperiência. O franqueado deseja aproveitar um modelo bem sucedido, uma marca conhecida, um processo já estruturado, uma cadeia de valor já estabelecida. Então, ele compra os direitos de uma franquia e reúne o seu sonho de ter um negócio próprio com o sonho de crescer rápido. Esta relação de interesses torna-se bastante conveniente para ambas as partes (HASHIMOTO, 2010).

No Brasil, existe uma lei específica para definir este tipo de negócio, é a Lei 8.955 de 15 de dezembro de 1994, na qual se observa que:

[...] Franquia empresarial é o sistema pelo qual um franqueador concede ao franqueado o direito de uso de marca ou patente, associado ao direito de distribuição exclusiva ou semi-exclusiva de produtos e serviços e, eventualmente, também o direito de uso da tecnologia de implantação e administração do negócio ou sistema operacional, desenvolvido ou detido pelo franqueador, mediante remuneração direta ou indireta, sem que fique caracterizado vínculo empregatício (BRASIL, 1994).

O franchising de formato de negócio tem como características principais a transferência de conhecimento sobre a operação do negócio, incluindo, por exemplo, um programa formal de treinamento, um manual operacional, com a descrição dos processos, das especificações técnicas, dos padrões de qualidade e uma estrutura que oferece apoio operacional ao franqueado.

Em contrapartida, o franqueado paga uma taxa inicial de franquia e de mensalidades correspondentes aos royalties ${ }^{i \prime}$ e/ou às contribuições para o fundo cooperado de propaganda, cobrados, em geral, sobre o faturamento ou sobre o custo dos produtos comprados. O franqueado torna-se a partir de então, proprietário de seu negócio, no qual investe o próprio capital, respeitando os padrões estabelecidos pela franqueadora. Afinal, a empresa franqueada representa a imagem da franqueadora diante dos consumidores. O relacionamento entre a franqueadora e a franqueada é formalizado por meio de um contrato de franquia (FOSTER, 1994).

Para Lucchesi, Merlo e Pitta (2005, p. 2) "no Brasil, onde as turbulências na economia são constantes e existem poucos incentivos a abertura de novos negócios, as franquias se constituem como uma boa alternativa de empreendimento".

PAGNONCELLI, V.; ZAMPIER, M. A.; STEFANO, S. R. Competências empreendedoras de proprietários franqueados de escolas de idiomas do interior do Paraná. Revista de 
Segundo Jain (1999, p. 472), existem quatro diferentes tipos de organizações de franquias, a saber:

- Franquia fabricante-varejista: ilustrada pelas concessionárias de veículos e postos de combustíveis;

- Franquia fabricante-atacadista: exemplificada pelas engarrafadoras da Coca-Cola, que apenas misturam os ingredientes em sua fase final e distribuem os produtos da empresa;

- Franquia atacadista-varejista: exemplificada por algumas redes de drogarias, criadas por atacadistas de remédios;

- Franquia varejista patrocinada por uma empresa de serviços: ilustrada por empresas como McDonald's e Hertz.

De acordo com esta classificação de Jain (1999), o foco deste estudo será dado para franquias varejistas patrocinadas por uma empresa de serviços. Assim, quando for citado o termo "franquia", ele irá se referir a esta definição.

A história do segmento de educação no franchising brasileiro a que se refere o presente estudo, se inicia em 1963, quando surgiu a primeira rede nacional de franquias, a escola de idiomas Yázigi. De acordo com Lucchesi, Merlo e Pitta (2005), o plano cruzado alavancou o negócio das franquias. Em 1990, com a abertura econômica do Brasil, ocorreu um surto de expansão desta forma de negócio.

Segundo Moreira (2010), as franquias de idiomas no Brasil se preparam para uma nova onda de crescimento puxada pela expansão da classe $\mathrm{C}$, pelo bom desempenho da economia brasileira e pelos grandes eventos esportivos que o Brasil sediará nos próximos anos. De acordo com a autora, atualmente existem dezessete opções destas franquias no Brasil, são elas: ALPS, FISK, CCAA, CNA, InFlux, Number One, Park, Quatrum, Seven, Skill, The Kids Club, UNS, Uptime, Wise Up, Wizard, Yázigi Internexus e Yes.

Christian Ambros, diretor de marketing de uma das maiores franquias de idiomas do Brasil, corrobora a afirmação anterior de Moreira (2010). Segundo ele, o aumento da procura dos cursos de inglês e espanhol pela classe $C$ ocorreu especialmente nos últimos anos. Ele fala ainda que a demanda tem sido gradativa, pois em 2005 sua escola possuía 15\% de alunos da classe C, em 2006 esse número 
aumentou para $20 \%$, no ano seguinte subiu para $30 \%$ e atualmente já são $50 \%$ do total de estudantes (LIMA et al. 2013).

Segundo Alcalá e Barbosa (2013), a Copa do Mundo de 2014 deveria causar um crescimento de $10 \%$ em relação ao ano passado nas escolas de idiomas, com base em estudo realizado pela Associação Brasileira de Franquias (ABF). Segundo as autoras, espera-se que a procura pelo curso de inglês aconteça principalmente por pessoas que queiram trabalhar diretamente com turistas estrangeiros que ficarão hospedados no país. A forma de atuação compreende taxistas, vendedores, guias turísticos e recepcionistas de hotéis, pois são o principal público alvo das escolas e, portanto, firmar parcerias com empresas desse ramo é a chave do negócio.

Apesar de o momento estar favorável para este investimento, não deixa de ser necessário que o empreendedor possua certas atitudes, capacidades e habilidades para administrar bem seus negócios, ou seja, competência é fundamental, portanto, será o tema abordado a seguir.

\section{Competências e Competências Empreendedoras}

Derivada do inglês competence, competência é definida como "uma condição ou qualidade de suficiência de conhecimentos, habilidades ou sucesso" (WEBSTER, 1999 apud PARDINI; BRANDÃO; SOUKI, 2008, p.30). De acordo com Man e Lau (2000), pode ser considerada, ainda, como uma característica superior que destaca os indivíduos, denominados competentes.

Para Zarifian (2001, p. 72), a competência define-se como "um entendimento prático de situações que se apoia em conhecimentos adquiridos e os transforma na medida em que aumenta a diversidade das situações". Conhecendo estes diferentes conceitos, torna-se necessário saber como essas competências acontecem ou de onde elas advêm.

De acordo com Pontes (2009), o modelo de gestão de pessoas baseado em competências prevê 0 desenvolvimento dessas competências, onde 0 comprometimento com o autodesenvolvimento contínuo é uma de suas características principais. Segundo a autora, esta é uma questão até de sobrevivência, pois as exigências do trabalho e as mudanças nas estratégias 
organizacionais exigem sempre o desenvolvimento de novas competências para atender as diferentes situações que surgem no dia a dia da organização.

Prahalad (1999) explica que esse desenvolvimento está associado a um processo de aprendizagem e se concentra em três níveis: o individual, grupos familiares e empresa. Segundo o autor, o foco do aprendizado não reside somente na capacidade analítica, mas também nos processos e os valores. Portanto, define como crucial a existência de processos que possam melhorar a capacidade das equipes de desenvolver habilidades especiais.

Politis (2005) argumenta que a experiência, e em particular a anterior em criação de negócios, é importante para que ocorra uma aprendizagem empreendedora, pois os conhecimentos advêm dessas mesmas experiências e influenciam as escolhas estratégicas feitas pelos empreendedores em seus novos negócios.

Já para Le Boterf (2003, p. 73), é "a partir de uma reflexão sobre suas práticas reais que o profissional, graças a um trabalho de abstração e de conceitualização, poderá reinvestir sua experiência em práticas e em situações profissionais diversas", ou seja, a partir da compreensão da realidade e da aprendizagem com a mesma.

Desta maneira, a aprendizagem torna-se um "processo ou o meio pelo qual se adquire a competência, enquanto a competência representa uma manifestação do que o indivíduo aprendeu" (FREITAS; BRANDÃO, 2006, p. 100), formando-se então, um ciclo vicioso.

Portanto, entende-se neste estudo que a competência pode ser nata e/ou resultante da aplicação de conhecimentos, habilidades e atitudes adquiridas pela pessoa em qualquer processo de aprendizagem.

$\mathrm{Na}$ bibliografia utilizada como base para estudo deste tema, descobriu-se que as competências encontram-se divididas em individuais, organizacionais e empreendedoras, as quais serão descritas na sequência.

Zarifian (2001) explica que as competências individuais são percebidas como um processo dinâmico que abrange as capacidades do indivíduo, formadas por conhecimentos, habilidades e atitudes ( $\mathrm{CHA})$ para a ação em uma dada situação complexa. A respeito das competências organizacionais, o autor as diferencia em: 
técnicas, que se refere a conhecimentos específicos sobre o trabalho; processuais, sobre o conhecimento dos processos de trabalho; da organização, na qual inclui saber organizar os fluxos de trabalho; de serviço e sociais, refletindo a autonomia, responsabilização e comunicação no ambiente de trabalho.

Partindo-se agora para as competências focadas neste trabalho, há as competências empreendedoras, as quais possuem como componentes na literatura de empreendedorismo, a capacidade de visualização do ambiente e os sistemas de relações sociais (FILION, 1991; PAIVA JÚNIOR et al., 2006).

Como visto anteriormente, o empreendedorismo abrange diversos tópicos do estudo das competências e apresenta, por pressuposto, a necessidade de profissionais que possam conciliar competências individuais e organizacionais. As competências empreendedoras têm por base essa interação, fazendo com que o profissional analise os dois focos desta questão (as competências individuais e as organizacionais).

Desta forma, as competências empreendedoras podem ser definidas como uma união entre conhecimentos, habilidades e atitudes que possibilitem a um indivíduo demonstrar sua visão, suas estratégias e ações na criação de valores (tangíveis ou intangíveis) para a sociedade (ANTONELLO, 2006).

Cooley (1990) desenvolveu em seus estudos, diferenciações de comportamentos e características empreendedoras entre empreendedores bem sucedidos e outros que não atingiram o mesmo patamar. $\mathrm{O}$ autor divide-as em três conjuntos de ações: realização, planejamento e poder. Esses conjuntos apontam uma série de competências caracterizadas por comportamentos manifestados pelo empreendedor frente aos desafios vivenciados em seu cotidiano.

Porém, neste estudo, o modelo adotado será o de Man e Lau (2000), para o qual as competências empreendedoras são distinguidas e divididas em seis, elencadas da seguinte forma:

a) Competências de Oportunidade: "ação de reconhecimento de uma oportunidade de negócios, seja esta uma nova atividade a ser desenvolvida pela empresa, uma nova maneira de inserção de produtos/serviços já existentes, ou mesmo uma nova empresa" (PAIVA JÚNIOR et al., 2006, p. 3). 
Segundo Stevenson e Gumpert (1985 apud PAIVA JÚNIOR; LEÃO; MELLO, 2003), para identificar esta competência, é necessário que o empreendedor utilize elementos de preparação da empresa e, ainda de acordo com os autores, existem fatores controláveis, que são: a vigilância, seleção da equipe de trabalho, estudos, risco de uma nova atividade e mudança de estilo de vida. Há também os fatores incontroláveis: os aspectos culturais, sociais e econômicos, as quais afetam a habilidade de um potencial empreendedor no sentido de reconhecer uma tal oportunidade.

b) Competências de Relacionamento: o relacionamento em rede é descrito como uma ação fundamental para o desenvolvimento profissional. Ela exige que o empreendedor possua "a capacidade de criação e fortalecimento de uma imagem de confiança, uma boa reputação, compromisso e conduta junto a redes de relacionamentos" (RING; VAN DE VEN, 1994; BRUSH, GREENE \& HART, 2002 apud PAIVA JÚNIOR et al., 2006, p. 3).

c) Competências Conceituais: quando se entende que os empreendedores são hábeis observadores, tanto das oportunidades do ambiente externo quanto dos aspectos internos da organização, cabe reconhecer que eles driblam etapas normais do processo decisório e desenvolvem ações velozes e intuitivas (MAN; LAU, 2000).

Empreendedores com competências conceituais são capazes de perceber situações por ângulos diferentes, de modo a encontrar alternativas inovadoras para a mesma questão como, por exemplo, quando outras pessoas estão vendo o mercado saturado, esses indivíduos podem descobrir nichos para penetrar nesse mercado e se adaptar a novas situações (MAN, 2006).

d) Competências Administrativas: a competência administrativa se refere à eficiente alocação de talentos, recursos físicos, financeiros e tecnológicos. Esse processo se desdobra em mecanismos de planejamento, organização, comando, motivação, delegação e controle (MAN; LAU, 2000).

e) Competências Estratégicas: relacionam-se às ações de escolha e implementação de estratégias organizacionais e constituem uma área 
importante do comportamento empreendedor. Refere-se tanto à visualização de panoramas de longo prazo como ao planejamento de objetivos e posicionamentos de médio prazo (MINTZBERG; AHLSTRAND; LAMPEL, 2000).

f) Competências de Comprometimento: são as que demandam a habilidade de manter a dedicação do dirigente ao negócio, sobretudo em situações adversas. Tal compromisso pode também ser ilustrado pela devoção ao trabalho árduo e pelo desejo de alcançar objetivos de longo prazo em detrimento dos ganhos de curto prazo. Ao lado disso, deve haver a capacidade de recomeçar a atividade empresarial, mesmo após situações de insucesso, ou a disposição de não abandonar o negócio no seu período de crescimento, mesmo na ocorrência de crises setoriais (MAN; LAU, 2000).

Este modelo de Man e Lau (2000) será utilizado neste estudo, uma vez que é o mais utilizado em estudos científicos, garantindo, desta forma, uma maior credibilidade.

$\mathrm{Na}$ seção a seguir, será descrita a metodologia utilizada para desenvolver este trabalho, ou seja, os caminhos que foram utilizados para a aplicação desta pesquisa.

\section{Metodologia}

Este estudo pretendeu analisar as competências empreendedoras de proprietários franqueados de escolas de idiomas das cidades do interior do Paraná, de acordo com o modelo de Man e Lau (2000) e com as expectativas futuras de crescimento. Para atingi-lo, foram elencados os cinco objetivos específicos citados anteriormente na introdução do artigo e na intenção de cumpri-los, foi elaborado um roteiro de entrevista que foi aplicado individualmente aos participantes e em seguida analisado também individualmente pela autoria, levando-se em conta cada entrevistado e suas respostas.

Para Smith, Thorpe e Lowe (1999, p. 73), a entrevista demonstra "como as pessoas constroem o significado e a significância das suas situações, da complexa 
estrutura pessoal de crenças e valores". Estas crenças e valores foram desenvolvidos ao longo das vidas dos entrevistados a fim de "ajudar a explicar e a prever eventos no mundo delas".

Tendo em vista o pequeno número de trabalhos no Brasil que abordam a formação e o desenvolvimento das competências empreendedoras na área educacional utilizando como base as categorias de competências do Modelo de Competências Empreendedoras de Man e Lau (2000), como é o caso de Zampier (2010), e também por não haver estudos relacionando esta mesma abordagem a franqueados de escolas de idiomas, este trabalho pretendeu elevar o conhecimento deste tema, podendo ser caracterizado como um estudo exploratório.

Segundo Mattar (1996) essa abordagem é denominada exploratória, uma vez que eleva o conhecimento do pesquisador sobre o tema que está sendo pesquisado, servindo como apoio para elencar as prioridades e gerar informações sobre as possibilidades práticas do desenvolvimento da pesquisa.

Cooper e Schindler (2003) denominam este tipo de estudo como descritivo, pois segundo eles, um estudo que procura identificar e descrever, neste caso as competências dos proprietários e dirigentes de franquias de idiomas do interior do Paraná, pode ser assim denominado.

Optou-se pela abordagem qualitativa, onde, de acordo com Creswell (2007), a pesquisa ocorre em um cenário natural e seu foco está nas percepções e experiências dos participantes, neste caso, dos relatos dos franqueados e como eles interpretam suas ações empreendedoras.

O presente estudo foi feito a partir da análise de estudos de caso, que de acordo com Yin (2005, p. 32), "é uma investigação empírica que investiga um fenômeno contemporâneo dentro de seu contexto da vida real, especialmente quando os limites entre o fenômeno e o contexto não estão claramente definidos". Seguiu-se ainda, a recomendação do mesmo autor que infere que a fim de obter resultados mais significativos, a pesquisa deve abranger no mínimo dois estudos de caso.

Segundo Neuman (1999), esta é uma pesquisa com perspectiva temporal de corte transversal, pois foi feita apenas uma vez, tendo seus dados coletados em apenas um encontro, ou seja, em um período de tempo curto, antes de serem 
transcritos e analisados (COLLIS; HUSSEY, 2005). É de aproximação longitudinal porque algumas informações obtidas referem-se a acontecimentos anteriores (NEUMAN, 1999) como, por exemplo, o que diz respeito à história profissional do franqueado, sua formação, suas decisões anteriores, seus ideais e motivações para a criação da empresa.

O universo de pesquisa deste estudo compreende nove franquias de idiomas, sendo quatro em Guarapuava e cinco em Pato Branco, aqui representada por uma amostra correspondente a quatro franquias, sendo duas da cidade de Guarapuava e duas de Pato Branco, ambas no Estado do Paraná.

A princípio, foram contatadas as quatro escolas de Guarapuava, porém por estarem passando por problemas particulares, as franqueadas não puderam participar deste estudo. Desta forma, buscou-se outras franquias na cidade de Pato Branco a fim de proporcionar maior conteúdo de dados coletados para serem analisados e maior confiabilidade nos resultados obtidos, conseguindo assim, mais duas entrevistas. Portanto, as franqueadas E1 e E2 são da cidade de Guarapuava/PR e E3 e E4 de Pato Branco/PR.

A pesquisa de campo foi realizada no início do mês de maio de 2014 e utilizou-se de entrevistas, as quais foram gravadas e transcritas a fim de possibilitar uma melhor análise dos dados obtidos.

\section{Resultados}

O propósito desta seção é discutir os resultados da pesquisa, levando em consideração os dados primários e secundários coletados, as observações realizadas e os elementos conceituais de pesquisa, visando cumprir os objetivos propostos no trabalho.

Primeiramente, analisou-se o perfil das quatro empreendedoras entrevistadas e depois o perfil das suas franquias. Em seguida, foram identificadas as competências empreendedoras elencadas por Man e Lau (2000) em cada uma destas empreendedoras. Na sequência, verificou-se a frequência com que essas competências puderam ser identificadas. Após, analisou-se de que maneira ocorre o processo de desenvolvimento das competências. Por fim, verificou-se a existência 
de expectativa de crescimento das franquias por parte de suas proprietárias, tendo em vista o aumento da classe $\mathrm{C}$ e a ocorrência das mais importantes competições esportivas do mundo no Brasil.

\section{Perfil das empreendedoras entrevistadas}

A seguir, apresenta-se uma síntese do perfil das quatro empreendedoras entrevistadas. Todas elas ocupam cargo de direção em suas franquias e duas atuam também como professoras. Verificou-se que todas possuem ensino superior completo, sendo três delas em Letras-Inglês e uma em Arte e Educação. Percebe-se assim, que todas possuem formação voltada para a sua área de atuação que é o ensino.

Cabe aqui destacar o que Dornelas (2008) sugere a respeito dos fatores associados a um maior índice de atividades empreendedoras atualmente, que são: percepção da oportunidade, fatores sociais e culturais, educação (Ensino Médio e Superior), participação das mulheres, experiência e suporte para os start-ups. Estes fatores foram identificados claramente neste estudo, principalmente no que se refere à participação das mulheres no mercado, pois todas as participantes deste estudo são do sexo feminino.

Com relação à faixa etária das empreendedoras, a E1 e a E4 possuem entre 30 e 34 anos, E3 entre 40 e 44 e E2 entre 50 e 54 anos. Apesar de duas possuírem menos idade, já possuem bastante tempo de experiência, pois E4 tem entre 12 e 14 anos de experiência e E1 entre 16 e 18 anos. A mais experiente é a $E 2$, que tem entre 28 e 30 anos e a última também com bastante tempo, E3 com 25 a 27 anos. A experiência profissional anterior das participantes era: E2 como proprietária de outra franquia, E1 como professora universitária e E3 e E4 como professoras de inglês, ou seja, todas entraram em um negócio em que já tinham algum tipo de experiência.

Cabe informar ainda, que todas são casadas e três delas citaram que possuem em suas famílias pais e maridos que atuam ou já atuaram como empreendedores, portanto, elas os têm como modelo de empreendedores que pretendem imitar. 
Como características importantes para gestão de uma franquia, as empreendedoras elencaram: criatividade, foco no trabalho e nos clientes, bom relacionamento com as pessoas e iniciativa. Dentre estas características a criatividade foi a que mais apareceu, corroborando com a afirmação de Filion (1999) de que o empreendedor é uma pessoa criativa e possui a capacidade de estabelecer e atingir objetivos, mantendo alto nível de consciência do ambiente em que vive.

\section{Perfil das franquias pesquisadas}

Nessa etapa, apresenta-se o perfil das quatro franquias participantes da pesquisa de campo. Duas pertencem à cidade de Guarapuava-PR e duas à cidade de Pato Branco-PR.

No que diz respeito ao porte e com relação ao faturamento, todas as franquias se enquadram como microempresas que, de acordo com o Art. $2^{\circ}$ da Lei no 9.317/96, são aquelas que possuem faturamento de até $R \$ 240.000,00 /$ ano (BRASIL,1996). Elas possuem entre 6 e 15 funcionários, perfazendo uma média de dez funcionários.

Das franquias pesquisadas, duas possuem sócios e três possuem familiares trabalhando ou de certa forma auxiliando na escola, uma delas como sócia, outra como professora e a outra como auxiliar administrativo, corroborando o que diz a literatura sobre a importância da família na vida dos empreendedores, seja apoiando e incentivando ou ajudando financeiramente (RAE, 2004).

A data de criação das franquias pesquisadas varia entre 1990 e 2010. No presente ano, elas possuem uma média de 192 alunos e houve pouca variação nos últimos três anos. Estes alunos são em sua grande maioria adolescentes, porém, uma delas tem foco nos universitários, outra nos adultos e outra em crianças. O tempo médio de permanência destes alunos nas escolas é de quatro anos. 


\section{Identificação das competências empreendedoras}

Neste momento, serão apresentadas as competências empreendedoras identificadas nas empreendedoras pesquisadas, de acordo com o modelo de Man e Lau (2000).

Para que as empreendedoras entrevistadas apresentassem a competência de oportunidade não bastaria apenas o fato de reconhecer uma oportunidade, mas são necessários elementos de preparação da empresa, dentre os quais existem os fatores controláveis: a vigilância, seleção da equipe de trabalho, estudos, risco de uma nova atividade e mudança de estilo de vida. Há também os fatores incontroláveis, que exigem uma maior atenção neste momento, são eles: aspectos culturais, sociais e econômicos, que afetam a habilidade de um potencial empreendedor (STEVENSON; GUMPERT, 1985 apud PAIVA JÚNIOR; LEÃO; MELLO, 2003).

No caso da E1, a oportunidade surgiu e ela soube aproveitar muito bem, pois já estava preparada. Ela já tinha proposto sociedade anteriormente para a franquia em que trabalhava como professora e cinco anos depois a ex-franqueada Ihe ofertou a escola, como se observa nestes comentários:

\footnotetext{
Antes de eu sair eu propus sociedade para ela, mas naquela época não era interessante pra ela, passou-se cinco anos e em uma conversa na Universidade, ela era também professora da Universidade, ela falou pra mim [...] vou vender a franquia, eu levantei a mão, falei eu quero.
}

A E2 identificou a oportunidade pelo fato de possuir uma franquia anteriormente por oito anos, então já conhecia o mercado amplamente e sabia que tinha espaço para sua escola. Segundo ela: "sempre existe um espaço para um trabalho bem feito". De acordo com a empreendedora, ela "se sentia com potencial para produzir" e ainda conhecia a marca de sua atual franquia, sabendo da qualidade que possuía. A marca era também reconhecida pelos demais concorrentes: "sempre soube o que era a escola $\mathrm{X}$, pois entre diretores de escolas de idiomas, a escola $X$ tem um conceito das melhores do país".

Assim, ela buscou fazer um estudo socioeconômico da cidade junto ao franqueador para visualizar se haviam condições de abrir esta escola na cidade. 
Constatou que a cidade não tinha o perfil adequado, mesmo assim, não quis perder a oportunidade e por ter clientes esperando por ela, foi contra o que tinha sido alertado pelo franqueador, acabou passando por dificuldades financeiras no início, mas que atualmente estão superadas. Estas questões podem ser observadas nas seguintes afirmações de E2:

O perfil socioeconômico da nossa cidade não tinha indicação de que era aconselhável abrir [...], só deixaram [...] pela história de eu estar vindo de uma outra franquia, de eu ter um número de clientes esperando que vieram comigo. [...], por eu estar preparada que eu não teria o lucro nos próximos três anos, então isso tinha um estudo sim, então fui bem alertada quanto a isso, mas é a cidade em que eu quero morar [...] foi bem difícil, foi horrível, trabalhei no vermelho por muito tempo, mas é eu sempre acreditei se eu tinha o melhor, se tudo o que é feito era impossível não ter público pra isso, e hoje tá ai.

Da mesma forma, E4 não fez uma pesquisa de mercado especificamente porque também já atuava na área, na escola de sua mãe. E4 tinha certeza que ainda havia espaço para uma franquia deste ramo na cidade e queria dar continuidade ao trabalho da família modernizando-o. Mas sua busca surgiu, principalmente, pelo interesse em obter o auxílio oferecido pelo franqueador. A pesquisa feita por E4 foi para verificar qual das franquias existentes no mercado se adaptava mais ao seu perfil dela e de seus colaboradores, que vieram junto com ela da outra escola. Estes relatos podem ser observados nas seguintes citações de E4:

Já trabalhava né com o segmento de escola de inglês, mas a gente achou que realmente trazer uma franquia pra cá ajudaria não só a gente na questão de trabalhar né com o negócio, mas, porque sozinho é muito complicado [...] então a ideia de trazer uma franquia foi em função disso, de auxiliar no nosso trabalho e dar continuidade na escola que já existia [...] mas com uma cara diferente [...] o que a gente fez foi uma pesquisa pra que a gente pudesse definir qual seria a melhor franquia pra gente trazer né, então a gente fez uma pesquisa em cima de sites da Associação Brasileira de Franchising, em vários segmentos da escola de inglês, entramos em contato com muitos franqueados também, pra saber se eles estavam satisfeitos ou não né, porque nós tínhamos certeza de que aqui ainda caberia uma escola de um porte maior né, Pato Branco tinha público pra isso.

Algumas das empreendedoras continuam até hoje a perceber novas oportunidades através de novos nichos de mercado ou uma nova maneira de

PAGNONCELLI, V.; ZAMPIER, M. A.; STEFANO, S. R. Competências empreendedoras de proprietários franqueados de escolas de idiomas do interior do Paraná. Revista de

Empreendedorismo e Gestão de Pequenas Empresas, v. 3, n. 3, p. 129-160, 2014. 
inserção de produtos/serviços já existentes (PAIVA JÚNIOR et al., 2006), como pode ser percebido pelas suas afirmações:

E2: o complemento escolar, que é o ensino de português e matemática, reforço, é um nicho bem interessante, e que no Brasil a gente tem só o KUMON fazendo isso, está nadando sozinho ai nesse mercado, (...) e mais ainda também a parte de intercâmbio.

E4: a questão dos eventos que vão acontecer no Brasil né, então Copa, o pessoal vai explorar muito a questão do inglês porque eles vão precisar de muita mão-de-obra, vão estar contratando e o pessoal vai sentir realmente que o Brasil tem uma carência disso, eu acho que pra nós ainda vai ser uma coisa muito proveitosa, muito importante esses eventos que vão acontecer né a curto prazo aqui no país.

A competência de relacionamento pode ser identificada também em três destas empreendedoras entrevistadas, a E1 destacou sua competência de relacionamento quando comentou o seguinte sobre seus funcionários: "eu tô com uma equipe boa, já tem um bom tempo [...] eu luto por eles, porque bons profissionais está em escassez no mercado". Sobre os pais de seus alunos: "os pais tem credibilidade comigo, eles confiam no meu trabalho". E ainda, ela mantém bom relacionamento com a concorrência: "Eu tenho um relacionamento muito bom com as outras escolas [...] A professora Rita [...] nós sempre estamos nos falando, já tentamos fazer algumas coisas juntas com as escolas e tal".

Esta competência em E2 destaca-se também por ela possuir um forte relacionamento com pessoas influentes no meio social a que pertence e desenvolver inúmeras atividades em prol da sociedade, como se constata em sua fala: "eu faço parte de uma ONG, O Clube Ser Otimista Internacional, há quase dez anos, e eu atuo na área de Boa Vontade Internacional, ontem mesmo a gente tava no projeto social, [...] o projeto 'Cidadãos do Mundo', que é inglês pra comunidade carente”.

Para E4, essa competência é muito percebida em seu relacionamento com os pais e alunos de sua escola:

A gente têm tentado trazer os pais pra dentro da escola o máximo possível, [...] porque quando os pais sabem realmente o que tá acontecendo dentro da escola, o trabalho da gente fica muito mais fácil né, senão acaba que as vezes o pai vira aquela pessoa que só paga [...] e eu acho que o que faz o aluno ficar na escola realmente é quando o pai, os alunos claro estão satisfeitos, mas principalmente o pai, porque ele tá sentindo que a escola tá buscando.

PAGNONCELLI, V.; ZAMPIER, M. A.; STEFANO, S. R. Competências empreendedoras de proprietários franqueados de escolas de idiomas do interior do Paraná. Revista de

Empreendedorismo e Gestão de Pequenas Empresas, v. 3, n. 3, p. 129-160, 2014. 
Estas empreendedoras evidenciam, desta forma, que possuem uma "capacidade de criação e fortalecimento de uma imagem de confiança, uma boa reputação, compromisso e conduta junto a redes de relacionamentos" (RING; VAN DE VEN, 1994; BRUSH; GREENE; HART, 2002 apud PAIVA JÚNIOR et al., 2006, p. 3).

A competência conceitual foi identificada neste estudo pela capacidade das empreendedoras em utilizarem suas intuições nas decisões sobre o empreendimento, pois elas driblam etapas normais do processo decisório e desenvolvem ações velozes e intuitivas, visualizando oportunidades mesmo em situações de crise do país. Enquanto outras pessoas estão vendo o mercado saturado, esses indivíduos podem descobrir nichos para penetrar nesse mercado e se adaptarem a novas situações, tornando-se hábeis observadores, tanto das oportunidades do ambiente externo quanto dos aspectos internos da organização.

A E4 tem a seguinte visão sobre o uso da intuição em seus empreendimentos: "tem que usar a intuição e, normalmente, eu acredito que por ter trabalhado com isso há tanto tempo em sala de aula também, tem funcionado". A E1 e a E2 afirmaram que também costumam agir de acordo com a intuição em muitos casos. E1 afirma que: "às vezes me dá uma cisma e se eu to cismada eu não faço".

Sobre a observação de oportunidades em momentos de crise, E1 afirmou que: "sempre num momento de crise existe uma oportunidade também" e complementa com o seguinte exemplo: "morreu pessoas, enquanto uns choram outros vendem lenços né, em todo momento de crise existe oportunidade e acho que cabe a nós empreendedores olhar com outros olhos esse momento de crise".

$\mathrm{Na}$ competência administrativa, que se refere à eficiente alocação de talentos, recursos físicos, financeiros e tecnológicos, desdobrando-se em mecanismos de planejamento, organização, comando, motivação, delegação e controle (MAN; LAU, 2000), todas as empreendedoras demonstraram esta competência com ações muito parecidas, pois pode ser observada uma eficiente maneira de alocar talentos na empresa pelo seguinte comentário da entrevista de E1:

PAGNONCELLI, V.; ZAMPIER, M. A.; STEFANO, S. R. Competências empreendedoras de proprietários franqueados de escolas de idiomas do interior do Paraná. Revista de

Empreendedorismo e Gestão de Pequenas Empresas, v. 3, n. 3, p. 129-160, 2014.148 
Eles passam por um processo de seleção e a gente vê [...] quem se adaptar melhor, a metodologia é que fica na empresa e não para por ai a avaliação [...] nós montamos uma sala de videoconferência e eu tenho os supervisores do Rio de Janeiro, da área de educação, é supervisionando as aulas dos meus professores a cada seis meses então, uma vez por semestre por videoconferência via Skipe, eles assistem as aulas dos meus professores, então é uma avaliação contínua de desempenho.

A respeito de investimentos em recursos físicos e tecnológicos, pode ser observado nos seguintes comentários de E3:

[...] temos que fazer reparos semestralmente, porque sempre há desgaste de algum equipamento e é um padrão de qualidade né, você tem que estar com tudo certinho, limpinho, organizado, então é frequente e às vezes bastante alta essa manutenção.

Percebe-se que as entrevistadas possuem visão de onde é necessário fazer investimentos. Sobre o uso de tecnologia E3 comenta: "é bastante eficiente né, ajuda muito, porque se não tiver vai ficar muito fora da realidade né".

Cabe ainda comentar que o franqueador também interfere nesse momento, pois exige certo padrão em todas as franquias e interfere também com sugestões de onde investir recursos financeiros, como se observa nos seguintes comentários de E3: "existe alguns critérios pré-estabelecidos, não vem impostos, mas como sugestão para a franquia, então, são percentuais que eles sugerem que a gente aplique no que e em que época do ano". E ainda segundo E4: "nós estamos definindo onde investir os recursos de acordo com o que a franquia vem nos exigindo né, então, nossa primeira meta é terminar de colocar a escola dentro do padrão".

Os mecanismos de planejamento, organização, comando, motivação, delegação e controle também são observados em todas as empreendedoras, mas poderão ser mais bem observados a seguir, nas competências estratégicas e de comprometimento.

A competência estratégica, que se refere tanto à visualização de panoramas de longo prazo como ao planejamento de objetivos e posicionamentos de médio prazo (MINTZBERG; AHLSTRAND; LAMPEL, 2000), foi percebida em todas as empreendedoras, uma vez que, segundo elas, conseguem se manter no caminho, 
quando fazem planejamento de longo prazo e possuem mecanismos eficientes no controle de metas, com grande acompanhamento também por parte do franqueador.

Nas empreendedoras 1, 2 e 4 foi percebida uma vontade muito grande de crescer e construir sua própria sede da escola, já que todas são alugadas. Isto pode ser percebido nas seguintes frases:

\footnotetext{
E1: daqui a um ano ter pelo menos duzentos alunos [...] daqui a cinco anos [...] estar entre as três primeiras de Guarapuava, sabe é assim que o pessoal, você pergunte-me o nome de uma escola de idiomas, e que a escola $\mathrm{V}$ venha a mente das pessoas.

E2: daqui a um ano [...] na minha própria sede. Daqui a cinco anos, [...] quem sabe a minha filha né tá assim completamente realizada e dando continuidade a esse trabalho.

E4: Daqui a um ano eu imagino ela realmente terminada, tudo dentro do padrão e em cinco anos a nossa meta é ter construída a nossa sede própria. [...] com o dobro de alunos e própria.
}

Por fim, a competência de comprometimento também foi verificada em todas as empreendedoras entrevistadas, apesar de E1 estar grávida, ela tem se utilizado de um importante mecanismo de sua competência administrativa para lidar com esse momento de sua vida, a delegação de poder, como se verifica em seu relato:

\begin{abstract}
Estou aprendendo a delegar, ainda mais agora por causa da gravidez não é fácil também, porque eu gosto de ter as coisas todas sobre o meu controle de saber de tudo e controlar tudo, mas isso não é bom, nem pra mim nem pra quem trabalha comigo né? Então esse ano eu fui na marra obrigada a delegar e supervisionar ao invés de ter tudo na minhas mãos, e tem dado certo.
\end{abstract}

A E2 também está passando por um novo momento em sua vida, tornou-se avó há pouco tempo e tem dedicado a maior parte de seu tempo à sua família. Porém, E2 está há dois anos trabalhando em um processo de sucessão, passando o comando da escola para a sua filha. Por isso, hoje em dia não se considera um exemplo de empresária: "minha filha tá assumindo totalmente, principalmente porque ela é sócia [...] mas eu poderia dedicar mais tempo". Apesar de que considera: "já poderia fazer isso que estou fazendo hoje", de deixar a escola nas mãos da filha, por ter preparado bem esse processo de sucessão.

De acordo com Man e Lau (2000), tal compromisso pode também ser ilustrado pela devoção ao trabalho árduo, verificado em E3 quando fala sobre o 
tempo dedicado ao seu empreendimento: "O dia todo, o dia todo e algumas noites, acho que é suficiente porque é o que tem, se tivesse mais eu ia ficar mais, com certeza".

Estas empreendedoras tiveram ainda, a capacidade de continuar a atividade empresarial mesmo após situações de insucesso que, segundo Man e Lau (2000) e Cooley (1990), também identificam-se nesta competência, pois todas encararam seus erros como um aprendizado e buscam a cada dia entender por que algo não funcionou em determinado momento e como fazer para melhorar.

\section{Frequência de ocorrência das competências empreendedoras}

Nesta seção será demonstrada a mensuração da frequência com que foram identificadas as competências empreendedoras elencadas por Man e Lau (2000) nas empreendedoras entrevistadas.

\begin{tabular}{|l|c|c|c|c|c|c|}
\hline \multirow{2}{*}{ COMPETÊNCIAS } & \multicolumn{3}{|c|}{ EMPREENDEDORAS } & \multicolumn{2}{c|}{ FREQUENCIA } \\
\cline { 2 - 7 } & $\mathrm{E} 1$ & $\mathrm{E} 2$ & $\mathrm{E} 3$ & $\mathrm{E} 4$ & Qtde. & $\%$ \\
\hline Oportunidade & $\mathrm{X}$ & $\mathrm{X}$ & & $\mathrm{X}$ & 3 & 75 \\
\hline Relacionamento & $\mathrm{X}$ & $\mathrm{X}$ & & $\mathrm{X}$ & 3 & 75 \\
\hline Conceituais & $\mathrm{X}$ & $\mathrm{X}$ & & $\mathrm{X}$ & 3 & 75 \\
\hline Administrativas & $\mathrm{X}$ & $\mathrm{X}$ & $\mathrm{X}$ & $\mathrm{X}$ & 4 & 100 \\
\hline Estratégicas & $\mathrm{X}$ & $\mathrm{X}$ & $\mathrm{X}$ & $\mathrm{X}$ & 4 & 100 \\
\hline Comprometimento & $\mathrm{X}$ & $\mathrm{X}$ & $\mathrm{X}$ & $\mathrm{X}$ & 4 & 100 \\
\hline
\end{tabular}

QUADRO 1 - Frequência com que cada competência é demonstrada pelas empreendedoras participantes

Fonte: Dados coletados em pesquisa.

Através do quadro 1, pode-se visualizar a frequência em que são identificadas as competências empreendedoras nas empreendedoras entrevistadas. Verifica-se por meio dele que as Competências Administrativas, Estratégicas e de Comprometimento tiveram maior ocorrência, pois foram identificadas em todas as empreendedoras, já as de Oportunidade, Relacionamento e Conceituais tiveram uma frequência menor, tendo sido identificadas apenas em três empreendedoras participantes do estudo.

Isso demonstra que ainda há necessidade de algumas empreendedoras desenvolverem suas competências para atingir melhores resultados em suas 
franquias. Nesse sentido, é importante salientar que as competências devem ser desenvolvidas e aprimoradas sempre, pois o mundo está em constante transformação.

\section{Desenvolvimento das competências empreendedoras}

$\mathrm{Na}$ presente pesquisa, a fim de explicar os meios pelos quais ocorre o processo de desenvolvimento das competências empreendedoras, levou-se em consideração a busca pelo empreendedor em estar se preparando para as suas atividades diárias. Identificou-se que o desenvolvimento está associado a um processo de aprendizagem (PRAHALAD, 1999) e à aquisição de novos conhecimentos, habilidades e atitudes, enfim, às consideradas competências.

O padrão de práticas encontrado no processo de desenvolvimento de competências das empreendedoras pesquisadas a partir de suas citações foi: a prática do dia a dia, estudos, cursos, treinamentos, congressos, leituras, experiência, erros e acertos, intuição, observação e relacionamento com pessoas, conforme pode ser observado no quadro 2.

\begin{tabular}{|c|c|}
\hline $\begin{array}{l}\text { EMPREEN- } \\
\text { DEDORAS }\end{array}$ & COMO DESENVOLVEM SUAS COMPETÊNCIAS EMPREENDEDORAS \\
\hline E1 & $\begin{array}{l}\text { Com os cursos e treinamentos ofertados pelo franqueador, lendo bastante, } \\
\text { conversando com pessoas mais experientes ou observando outros } \\
\text { empreendedores e, na tentativa e erro. }\end{array}$ \\
\hline E2 & $\begin{array}{l}\text { Trocando informações das áreas que gosto com outras pessoas, me dedicando } \\
\text { nos cursos oferecidos pelo franqueador, os quais acontecem a cada dois meses, } \\
\text { lendo, assistindo TV, filmes e internet. }\end{array}$ \\
\hline E3 & $\begin{array}{l}\text { Através de cursos, treinamentos, simpósio, congressos e muita leitura, além de no } \\
\text { dia a dia, na prática. }\end{array}$ \\
\hline \multirow{3}{*}{ E4 } & $\begin{array}{l}\text { Através de treinamentos, de dicas dadas pelo franqueador, as vezes tentando } \\
\text { mesmo, acredito que esse desenvolvimento ocorre todos os dias por estar } \\
\text { trabalhando com pessoas e por isso sempre aprendendo. E ainda, lendo jornais e } \\
\text { revistas e buscando ficar em dia com as informações da área de atuação. }\end{array}$ \\
\hline & $\begin{array}{l}\text { Acredito que hoje em dia não há mais muito espaço para fazer as coisas com os } \\
\text { olhos fechados, que é necessário algum parâmetro, e por isso utilizo com } \\
\text { frequência do suporte do franqueador. }\end{array}$ \\
\hline & $\begin{array}{l}\text { Acredito que a melhor fonte para aprender são as empresas que oferecem esse } \\
\text { suporte, no caso, o próprio franqueador e o SEBRAE, que oferece cursos na área. }\end{array}$ \\
\hline
\end{tabular}

QUADRO 2 - Processo de desenvolvimento das competências empreendedoras.

Fonte: Dados coletados em pesquisa.

PAGNONCELLI, V.; ZAMPIER, M. A.; STEFANO, S. R. Competências empreendedoras de proprietários franqueados de escolas de idiomas do interior do Paraná. Revista de

Empreendedorismo e Gestão de Pequenas Empresas, v. 3, n. 3, p. 129-160, 2014. 
Percebe-se que a partir do momento em que as empreendedoras adquirem um entendimento prático de situações, se apoiam em conhecimentos adquiridos e os transformam. Assim, na medida em que aumentam a diversidade das situações, desenvolvem cada vez mais suas competências (ZARIFIAN, 2001).

Cabe ressaltar ainda, a importância da experiência anterior. Das empreendedoras pesquisadas, destaca-se E2 com experiência anterior de criação de negócios, dentre outras. A experiência anterior é importante para que ocorra uma aprendizagem empreendedora, pois os conhecimentos advindos influenciam as escolhas estratégicas feitas pelos empreendedores em seus novos negócios, tornando-se um fator também a ser considerado no desenvolvimento das competências (POLITIS, 2005).

Visualiza-se que estas empreendedoras possuem um estímulo muito grande para que assumam o seu próprio desenvolvimento (DUTRA, 2008)que advém de seus franqueadores, com oferta de cursos presenciais e até mesmo à distância. Com isso, adquirem um comprometimento com o autodesenvolvimento contínuo. Importante destacar que esse desenvolvimento de suas competências é essencial para que possam atender as diferentes situações que surgem no dia a dia da organização da melhor forma possível (PONTES, 2009).

Portanto, constatou-se que o desenvolvimento das competências dessas empreendedoras ocorre a partir de uma reflexão sobre suas práticas reais e de um trabalho de abstração e conceitualização. Em consequência, estas empreendedoras reinvestem suas experiências em práticas e situações profissionais que variam no dia a dia (LE BOTERF, 2003).

Percebe-se, enfim, que neste estudo, todas as empreendedoras entrevistadas buscam desenvolver suas competências ao longo de suas práticas no dia a dia. Desta forma, constata-se que elas não são somente natas, uma vez que em nenhum dos casos as empreendedoras, desde que passaram a ser assim denominadas, deixaram de buscar alguma forma de aprendizado para fazer suas tarefas diárias. 


\title{
Expectativa de crescimento das franquias
}

Buscando verificar se as empreendedoras franqueadas possuem expectativas de crescimento devido à expansão da classe $\mathrm{C}$ e pelos grandes eventos esportivos que o Brasil sediará nos próximos anos, foram obtidas informações que serão relatadas nesta seção.

Em um primeiro momento, sobre a percepção de aumento de alunos devido à esta expansão da classe $\mathrm{C}$, as entrevistadas fizeram os seguintes comentários:

\begin{abstract}
E1: Sim, tanto que eu digo que o meu público aqui é B e C, sabe? Eu vi que os pais estão mais, [...] estão mais preocupados com o futuro dos filhos e como hoje em dia o inglês passou [...] o inglês há dez, quinze anos atrás era um luxo que você tinha, hoje é uma necessidade.

E2: Percebi, e eles são superdedicados, quando tem, tenho alunos assim, são os pais que investem na educação, são os pais que não, eu não tenho problema com indisciplina, com inadimplência, tenho sim.

E3: Muito pequeno mas percebi, ainda é pequeno, mas está melhor do que alguns anos atrás sim.

E4: Eu acredito que hoje a maior parte dos nossos alunos seja da classe C [...] a ideia hoje de oferecer inglês está $90 \%$ voltada pra classe C porque eles é que precisam do inglês pra ter um trabalho melhor, tentar uma promoção dentro do trabalho.
\end{abstract}

Analisando suas afirmações, percebeu-se que todas as entrevistadas sentiram este impacto da expansão da classe C, principalmente pelo fato de os pais, que possivelmente não tinham condições anteriormente e que por terem atingido uma melhor condição de vida atualmente, procurarem investir em seus filhos (E1 e E2). Algumas empreendedoras dizem ainda que já são seu público principal, como pode ser visto na afirmação de E1 e de E4.

Assim, todas as empreendedoras estão em consonância com o que diz a literatura pesquisada e referenciada neste trabalho. De acordo com Lima et al. (2013) houve um aumento da procura por cursos de inglês nos últimos anos. Esse aumento foi gradativo nas franquias de idiomas do Brasil. Em uma das maiores franquias do país, existiam 15\% de alunos da classe C em 2005. Já em 2006 existiam 20\%. No ano seguinte, havia 30\% e atualmente já são $50 \%$ do total de estudantes.

Percebeu-se também que existe expectativa por parte da maioria das empreendedoras pesquisadas com relação ao aumento de alunos e faturamento em 
razão das competições esportivas que serão sediadas pelo Brasil, sendo que uma delas, a E2, inclusive já vende um curso especificamente segmentado para esse público, ou seja, a expectativa já está se tornando realidade. Relata-se a seguir as afirmações das entrevistadas sobre este assunto:

E1: Curitiba já está tendo essa demanda então eu espero que atinja o interior do Paraná também, então é uma expectativa para os próximos meses.

E2: Sim, até nós nos preparamos com um curso específico agora pra esse público adulto acima de dezoito anos, que é fazer seis estágios em dezoito meses e é um projeto programado só pra essa época pra essa fase que vem ai e consequentemente quando eu divulguei eu tive a resposta e ta funcionando.

E4: Tenho uma expectativa de que realmente vai aumentar o nosso número de alunos por causa disso.

Portanto, verificou-se que estas empreendedoras acreditam que a Copa do Mundo de 2014 e as Olimpíadas de 2016 devem causar um crescimento nas escolas de idiomas, conforme o estudo realizado pela Associação Brasileira de Franquias (ABF). A ABF sugere que este aumento será de 10\% (ALCALÁ; BARBOSA, 2013).

Uma das entrevistadas corrobora ainda com o que Alcalá e Barbosa (2013) inferem sobre o público principal que buscará pelo curso de inglês: taxistas, vendedores, guias turísticos e recepcionistas de hotéis. Ela também acredita que firmar parcerias com empresas desse ramo é a chave do negócio. Este fato pode ser percebido com a seguinte afirmação de E1: "tem empresas de táxi que já procuraram fazer cotação entre as franquias, entre as diferentes escolas de idiomas e ver o que eles podem oferecer para os próximos dois anos".

Estas empreendedoras percebem que este é o momento mais propício para este setor de franquia, o setor de escola de idiomas. Porém, como não sentiram nada concreto, E3 e E4 fizeram os seguintes comentários sobre o perfil dos brasileiros:

E3: acho que o brasileiro costuma deixar tudo pra última hora né, então pode ser que aconteça.

E4: eu acredito que como o brasileiro é um povo que realmente deixa tudo pra última hora, quando começarem a demandarem de mão de obra, precisarem de pessoas que precisam falar o inglês, ai é que o povo vai correr atrás.

PAGNONCELLI, V.; ZAMPIER, M. A.; STEFANO, S. R. Competências empreendedoras de proprietários franqueados de escolas de idiomas do interior do Paraná. Revista de

Empreendedorismo e Gestão de Pequenas Empresas, v. 3, n. 3, p. 129-160, 2014. 
Apenas E3 demonstrou-se um pouco pessimista com esta possível oportunidade, como pode ser visto em sua afirmação: "aqui acho difícil, conhecendo o perfil do pessoal da nossa região, acho pouco difícil que vá ter alguma interferência".

\section{Considerações finais}

Antes de tudo, é preciso lembrar que o presente estudo analisou as competências empreendedoras dos proprietários franqueados de escolas de idiomas de acordo com o modelo de Man e Lau (2000). Para tanto, deu-se início com a apresentação de referenciais sobre o tema empreendedorismo e o conceito de empreendedor, relacionando-os com o foco do presente estudo, o empreendimento de franquias para, em seguida, abordar as competências e, enfim, as competências empreendedoras.

Visando atingir este objetivo geral, foi necessário contemplar o primeiro objetivo específico, 0 de conhecer o perfil do objeto de pesquisa, os empreendedores e suas franquias para, em seguida, identificar as competências nestes empreendedores, partindo dos conceitos citados por Man e Lau (2000).

Para cada competência empreendedora, foram elaboradas questões visando identificá-las ou não, analisando-as e comparando-as, a fim de verificar se suas respostas correspondiam ou estavam de acordo com o conceito do referido autor. Conforme o número de vezes em que essas respostas correspondiam, as competências eram identificadas e então mensuradas para atingir o segundo objetivo, o de verificar a frequência com que cada competência era identificada nos empreendedores participantes.

Em seguida, tomando por base o referencial teórico deste estudo a respeito do desenvolvimento das competências, buscou-se verificar se essas empreendedoras as desenvolviam ou não e, em caso afirmativo, de que forma o faziam. Por fim, verificou-se a existência de expectativas por parte dos franqueados, de crescimento das franquias pesquisadas, tendo em vista o aumento da classe $\mathrm{C}$ e a ocorrência das mais importantes competições esportivas do mundo no Brasil nos 
próximos anos, indagando-os sobre a percepção de aumento de alunos e faturamento, bem como a expectativa para essa possibilidade.

Ao analisar os dados coletados, pode-se elaborar um mapeamento de seus perfis e perceber as suas competências empreendedoras. Elas foram identificadas em sua totalidade na maioria das empreendedoras, mais precisamente em $75 \%$ dos casos pesquisados. Para tanto, levou-se em consideração as suas capacidades, habilidades e aptidões demonstradas nas atitudes das rotinas de trabalho, narradas pelas empreendedoras nas entrevistas.

Percebeu-se que a expectativa de crescimento é real e uma empreendedora inclusive já está concretizando esta expectativa com a oferta de um curso específico para o público que irá participar dos jogos sediados pelo Brasil e também em razão do aumento da classe $\mathrm{C}$, que para algumas empreendedoras já faz parte do principal público alvo.

Portanto, considera-se que o objetivo deste estudo foi cumprido, uma vez que todos os objetivos foram integralmente atingidos. Destaca-se, porém, que o assunto deste estudo não está esgotado, há espaço para um maior aprofundamento ou uma continuidade com um número maior de entrevistados. Pode-se ainda, realizar uma réplica em outro tipo de franquias ou outras formas de empreendimentos.

\section{Referências}

ALCALÁ, J.; BARBOSA, R. Escolas de idiomas devem crescer $10 \%$ com a Copa de 2014 2013. $<$ Disponível em: http://www.metodista.br/rronline/noticias/economia/2010/07/escolas-de-idiomasdevem-crescer-10-com-a-copa>. Acesso em: 14 maio 2013.

ANTONELLO, C. S. Aprendizagem na ação revisitada e sua relação com a noção de competência. Comportamento Organizacional e Gestão, v. 12, n. 2, p. 199-220, 2006.

BRASIL. Leis e Decretos. Lei no 9.317, de 05 de dezembro de 1996. Diário Oficial da União, Brasília, n. 973/7 p. 25 de 06 dez. 1996.

BRASIL. Leis e Decretos. Lei o 8.955, de 15 de dezembro de 1994. Diário Oficial da União, Brasília, n. 8955, 16 dez. 1994. 
COLLIS, J.; HUSSEY, R. Pesquisa em Administração: Um guia prático para alunos de graduação e pós-graduação. 2. ed. Porto Alegre: Bookman, 2005.

COOLEY, L. Entrepreneurship Training and the Strengthening of Entrepreneurial Performance. Final Report. Contract No. DAN-5314-C-00-3074-00. Washington: USAID, 1990.

COOPER, D. R.; SCHINDLER, P. S. Métodos de pesquisa em administração. 7. ed. Porto Alegre: Bookman, 2003.

CRESWELL, J. W. Projeto de Pesquisa: Métodos qualitativo, quantitativo e misto. 2. ed. Porto Alegre: Artmed, 2007.

DORNELAS, J. C. A. Empreendedorismo: Transformando ideias em negócios. 3. ed. Rio de Janeiro: Elsevier, 2008.

DUTRA, J. S.. Competências - conceitos e instrumentos para a gestão de pessoas na Empresa Moderna. São Paulo: Atlas, 2008.

FILION, L. J. Empreendorismo: Empreendedores e proprietários-gerentes de pequenos negócios. Revista de Administração de Empresas - RAE, São Paulo, v.34, n.2, p.05-28, abr./jun. 1999.

FILION, L. J. O Planejamento do seu Sistema de Aprendizagem Empresarial: Identifique uma Visão e Avalie o seu Sistema de Relações. Revista de Administração de Empresas - RAE, São Paulo, 1991.

FOSTER, D. L. O livro completo de franchising. Rio de Janeiro: Infobook, 1994.

FREITAS, I. A. de.; BRANDÃO, H. P. Trilhas de aprendizagem como estratégias de TD\&E. In: BORGES-ANDRADE, J. E.; ABBAD, G. DA S.; MOURÃ̃O, L. Treinamento, desenvolvimento e educação em organizações e trabalho: Fundamentos para a gestão de pessoas. Porto Alegre: Artmed, 2006, p. 97-113.

GUEDES, D. S.; TRIGO, V. O impacto do suporte oferecido pelos franqueadores no desempenho dos franqueados - Um estudo sobre o segmento de educação do Brasil. Estratégia e Negócios, Florianópolis, v. 2, n. 1, jan./jun. 2009. Disponível em: <http://portaldeperiodicos.unisul.br/index.php/EeN/index>. Acesso em: 29 mar. 2013.

HASHIMOTO, M. Franquias e empreendedorismo, 2010. Disponível em: <http://www.administradores.com.br/informe-se/artigos/franquias-eempreendedorismo/46301/>. Acesso em: 03 abr. 2013.

JAIN, S. C. Marketing planning \& strategy. 6 ed. Ohio: South-Western College Publishing, 1999.

PAGNONCELLI, V.; ZAMPIER, M. A.; STEFANO, S. R. Competências empreendedoras de proprietários franqueados de escolas de idiomas do interior do Paraná. Revista de Empreendedorismo e Gestão de Pequenas Empresas, v. 3, n. 3, p. 129-160, 2014. 
LE BOTERF G. Desenvolvendo a competência dos profissionais 2. ed. Porto Alegre: Artmed, 2003.

LIMA, L.; GRIECO, F.; GARCIA, H.; GASPARINDO, L. Fisk acompanha crescimento do consume da classe $C$ e conquista novos alunos, 2013. Disponível em: <http://www.tramaweb.com.br/cliente_ver.aspx?ClientelD=183\&NoticialD=5321>. Acesso em: 15 maio 2013.

LUCCHESI, C. A. M., MERLO, E. M. e M., PITTA, D. S. Os motivos envolvidos na internacionalização de franquias brasileiras. FACEF PESQUISA, v. 8, n. 2, 2005.

MAN, T. W. Y. Exploring the behavioural patterns of entrepreneurial learning: A competency approach. Education e Training, v. 48, n. 5, p. 309-321, 2006.

MAN, T. W. Y.; LAU, T. Entrepreneurial competencies of SME owner/managers in the Hong Kong services sector: A qualitative analysis. Journal of Enterprising Culture, v. 8, n. 3, p. 235-254, set. 2000.

MATTAR, F. N. Pesquisa de Marketing. 3. ed. v. 1. São Paulo: Atlas, 1996.

MINTZBERG, H.; AHLSTRAND, B.; LAMPEL, J. Safári de estratégia: Um roteiro pela selva do planejamento estratégico. Porto Alegre: Bookman, 2000.

MOREIRA, D. 17 opções de franquias de ensino de idiomas, setor que entra em uma nova onda de expansão. Revista Exame. Ed. 982, 2010. Disponível em: $<$ http://exame.abril.com.br/pme/noticias/franquias-de-ensino-de-idioma?p=17>. Acesso em: 05 mar. 2013.

NEUMAN, W. L. Social research methods: Qualitative and quantitative approaches. 3. Ed. Boston: Allyn and Bacon, 1999.

PAIVA JÚNIOR, F. G.; GUERRA, J. R. F.; OLIVEIRA, M. A. F. de; ALVES, V.S. A contribuição das competências empreendedoras para a formação de dirigentes em sistemas de incubação. In: Encontro Nacional de Estudos da Engenharia de Produção, 26, 2006. Fortaleza. Anais... Fortaleza/CE: ENEGEPE, 2006.

PAIVA JÚNIOR, F. G.; LEÃO, A. L. M. de S.; MELLO, S. C. B. Competências empreendedoras em comportamentos de dirigentes de êxito socialmente reconhecido. In: Encontro da Associação Nacional dos Programas de Pós Graduação em Administração, 27, 2003. Atibaia. Anais... Atibaia/SP: ANPAD, 2003.

PARDINI, D. J.; BRANDÃO, M. M.; SOUKI, G. Q. Competências empreendedoras e sistema de relações sociais: A dinâmica dos construtos na decisão de empreender nos serviços de fisioterapia. Revista de Negócios. Blumenau/SC; v. 13, n. 1, p. 2844, jan./mar. 2008.

POLITIS, D. The process of entrepreneurial learning: A conceptual framework. Entrepreneurship Theory and Practice, v. 29, n. 4, p. 399-424, jul. 2005.

PAGNONCELLI, V.; ZAMPIER, M. A.; STEFANO, S. R. Competências empreendedoras de proprietários franqueados de escolas de idiomas do interior do Paraná. Revista de

Empreendedorismo e Gestão de Pequenas Empresas, v. 3, n. 3, p. 129-160, 2014. 
PONTES, D. M. G. Desenvolvimento de competências no Banco do Brasil: Um estudo de caso na agência Carambei. Porto Alegre. Dissertação - Programa de PósGraduação em Administração - Universidade Federal do Rio Grande do Sul, 2009. Disponível

em: $<$ http://www.lume.ufrgs.br/bitstream/handle/10183/26277/000743714.pdf?sequence= 1>_Acesso em: 15 abr. 2013.

PRAHALAD, C. K. Reexame de competências. HSM Management, São Paulo, n. 17, p.42-52, nov. /dez. 1999.

RAE, D. Entrepreneurial learning: A practical model from the creative industries. Education + Training, v. 46, n. 8/9, p. 492-500, 2004.

RING, P. S.; VAN DE VE A. H. Developmental Processes of Cooperative Interorganizational Relationships. Academy of management, v. 19, n. 1, p. 90-118, jan. 1994.

SMITH, M. E.; THORPE, R.; LOWE A. Pesquisa gerencial em Administração. São Paulo: Pioneira, 1999.

TIMMONS, J. A. New venture creation. Burr Ridge, III.: Richard D. Irwin, 1994.

YIN, R. K. Estudo de caso: Planejamento e métodos. 3. ed. Porto Alegre: Bookman, 2005.

ZAMPIER, M. A. Desenvolvimento de competências empreendedoras e Processos de aprendizagem empreendedora: Estudo de casos MPE's do Setor Educacional, 2010. Dissertação de Mestrado. Disponível em: <http://dspace.c3sl.ufpr.br:8080/dspace/handle/1884/23979>. Acesso em: 10 jan. 2013.

ZARIFIAN, P. Objetivo competência: Por uma nova lógica. São Paulo: Atlas, 2001.

Artigo recebido em: 22/06/2014. Artigo aprovado em: 16/10/2014

NOTAS

i Franchising expressão inglesa que significa franquia. Deriva, etimologicamente, da expressão francesa franchise.

ii Royalties é de origem inglesa e se refere a uma importância cobrada pelo proprietário de uma patente de produto, processo de produção, marca, entre outros, ou pelo autor de uma obra, para permitir seu uso ou comercialização.

PAGNONCELLI, V.; ZAMPIER, M. A.; STEFANO, S. R. Competências empreendedoras de proprietários franqueados de escolas de idiomas do interior do Paraná. Revista de 